\title{
Investigation on the extractability of melanoidins in portioned espresso coffee
}

\author{
C. Bartel', M. Mesías², F.J. Morales² \\ 'Henriette Schmidt-Burkhardt Chair of Food Chemistry, University of Erlangen-Nuremberg, Erlangen, \\ Germany \\ ${ }^{2}$ Institute of Food Science, Technology and Nutrition, ICTAN-CSIC, José Antonio Novais I0, 28040 Madrid, \\ Spain
}

\section{ABSTRACT}

Coffee melanoidins have attracted interest as a result of its potential health benefits. This investigation aims to elucidate the extraction behavior of melanoidins and their populations during the preparation of portioned espresso coffee and its relationship with the antioxidant activity of the coffee brew. Filter-paper pods, FAP capsule, and clone capsule containing light roasted coffee have been investigated. An accumulative fractionation approach has applied to model the extraction kinetics of melanoidins, melanoidin populations, browning, chlorogenic acids (CGA), and antioxidant activity. Melanoidins were very efficiently extracted in clone capsules since less than $9 \mathrm{~s}$ was necessary to extract the $50 \%$ of the melanoidin content as compared with pods and FAP capsules, and the kinetic of extraction is slower than CGA. The extraction profile of melanoidins and browning fitted better with the antioxidant capacity than CGA and total solids profile. Melanoidin populations were obtained according to ethanol solubility. Total melanoidin content and the ratio between melanoidin populations did not change during extraction volume for espresso coffee. Melanoidin populations soluble at $75 \%$ ethanol showed the highest antioxidant activity. However, melanoidins with higher antioxidant activity are extracted at higher volumes. This investigation could make possible the adjustment of the technological requirements of espresso coffeemakers to produce an espresso coffee with high levels of beneficial compounds.

KEYWORDS: Espresso coffee, Portioned coffee, Pods, Melanoidins, Antioxidant capacity, Extraction, Kinetics.

\section{INTRODUCTION}

In addition to the stimulatory properties, coffee consumption is related to certain health benefits, such as anti-inflammatory and antimutagenic effects, reduction of cardiovascular risk, rheumatologic diseases, endometrial tumors, Parkinson's disease, Alzheimer's disease, and the regulation of insulin or body weight, among other (Bichler et al., 2007; Cavin et al., 2008; Lindsay et al., 2002; Morales, Somoza, \& Fogliano, 20I2; Ranheim \& Halvorsen, 2005; Salazar-Martinez et al., 2004; Wang, Qian, \& Yao, 20II). Coffee brew is a source of caffeine, hydroxycinnamates, particularly chlorogenic acids (CGA), antioxidants and indigestible fiber (Díaz-Rubio \& Saura-Calixto, 2007; Farah \& Donangelo, 2006; Manach, Scalbert, Morand, Rémésy, \& Jiménez, 2004). Some of the positive physiological effects of coffee consumption have been explained by the antioxidant properties of its constituents, such as the presence of phenolic compounds and Maillard reaction products (Borrelli, Visconti, Mennella, Anese, \& Fogliano, 2002; Daglia, Papetti, Gregotti, Bertè, \& Gazzani, 2000; Delgado-Andrade, Rufián-Henares, \& Morales, 2005). Human trials considering the Italian consumer average coffee intake ( 5 cups of espresso per day) found that coffee was able to significantly increase plasma glutathione concentration (Esposito et al., 2003). The contribution of coffee consumption to the overall intake of antioxidants may reach up to $70 \%$ in Western diets (Torres \& Farah, 2010) but also represents a significant portion of daily intake of fiber (Díaz-Rubio \& Saura-Calixto, 2007).

During the roasting of coffee green beans chemical and structural changes take place as a result of the Maillard reaction, caramelization and pyrolysis. The first consequence of roasting is the loss of thermolabile compounds such as trigonelline and chlorogenic acids in a different extent according to the roasting degree and also the formation of new compounds such as melanoidins (Farah, de Paulis, Trugo, \& Martin, 2005; Illy \& Viani, 2005). Melanoidins are high molecular weight (HMW) Maillard reaction end-products, which are a 
heterogeneous mixture of brown colored, nitrogen containing polymers, formed through the reaction of reducing sugars with proteins/amino acids (Moreira, Nunes, Domingues, \& Coimbra, 2012). Coffee polysaccharides, galactomannan-like and arabinogalactan-like carbohydrates, proteins, and phenolic compounds, mainly hydroxycinnamates, contribute to the formation of coffee melanoidins (Bekedam, Schols, van Boekel, \& Smit, 2008; Moreira et al., 2012; Nunes \& Coimbra, 2007). Coffee brew is one of the main sources of melanoidins in the human diet and the intake of coffee melanoidins estimated to range between 0.5 and $2.0 \mathrm{~g}$ per day for moderate and heavy consumers, respectively (Fogliano \& Morales, 20II). The impact of melanoidins to coffee brew is not limited to their color contribution since these molecules are involved in the modulation of flavor release, antioxidant and metal-chelating properties, and dietary fiber behavior (Hofmann, Czerny, Calligaris, \& Schieberle, 200I; Morales et al., 2012; Moreira et al., 2012; Reichardt, Gniechwitz, Steinhart, Bunzel, \& Blaut, 2009). Therefore, melanoidins (including also melanoproteins from bakery products) may contribute $20.2 \%$ to the daily antioxidant capacity intake, more than $50 \%$ corresponding directly to coffee melanoidins (Pastoriza \& Rufián-Henares, 2014). Silván,Morales, and Saura-Calixto (2010) suggested a new definition of coffee melanoidins as a maillardized fiber with potential beneficial effects on gastrointestinal health by combining the antioxidant activity of melanoidins and the low transit of these polymers (Borrelli, Esposito, Napolitano, Ritieni, \& Fogliano, 2004). Indeed, condensation of phenolic compounds with indigestible polysaccharides and melanoidins present in coffee could explain the association between coffee consumption and the antioxidant capacity of feces from healthy subjects (Garsetti, Pellegrini, Baggio, \& Brighenti, 2000).

There are many different devices and methods to produce coffee brew, which are generally characterized by extraction pressure, extraction process, extract/cup volume, and solid content (Parenti et al., 20l4; Petracco, 2005). There is not established an official definition for espresso coffee but it could be described as the brew obtained by percolation of hot water under pressure through compacted cake of roasted ground coffee, where the energy of the water pressure is spent within the cake (Illy \& Viani, 2005). During espresso brewing, water at approximately 9 bars and $88-92{ }^{\circ} \mathrm{C}$ is forced to go through coffee grounds compacted in a small brewing chamber (coffee cake) (Albanese, Di Matteo, Poiana, \& Spagnamusso, 2009). Temperature, pressure, brewing time, coarse grind and ground coffee portion, cake shape and moistening, and water quality, among others, have an influence on the physical and sensorial properties of the espresso coffee and the effectiveness of the extraction process (Albanese et al., 2009; Petracco, 2005). The overall quality of espresso coffee depends largely on the quality of the roasted coffee, but also on the extraction procedure.

Extensive studies have been focused on the effect of different physical variables during the percolation process on the extraction of caffeine, CGA, key aroma compounds and sensory analysis (Andueza, de Peña, \& Cid, 2003; Andueza et al., 2002; Gloess et al., 2013; Illy \& Viani, 2005; López-Galilea, de Peña, \& Cid, 2007; López-Galilea, Fournier, Cid, \& Guichard, 2006; Maeztu et al., 200I). Ludwig et al. (2012) investigated the extraction behavior of the main coffee antioxidants (caffeoylquinic acids, melanoidins, and caffeine) and the antioxidant capacity, during brewing time in the most widely consumed coffee brew methods (filter and espresso) in coffee. This investigation concluded that more than $70 \%$ of the antioxidants (except dicaffeoylquinic acid) of an espresso coffee were extracted during the first $8 \mathrm{~s}$.

Nowadays, portioned coffee is being well accepted by consumer and a number of commercial brands of single-dose and formats are already present in the market. Recently, Mestdagh, Davidek, Chaumonteuil, Folmer, and Blank (2014) reported the kinetics of coffee aroma extraction during espresso coffee preparation by applying an accumulative approach for fraction collection. To our knowledge, investigation on the extraction of melanoidins in filtered and espresso coffee is scarce, and they were considered as the browning rate and samples where sequentially collected during coffee brewing (Ludwig et al., 2012). Then a complete understanding of the kinetic of melanoidins extraction during preparation of espresso coffee is missing. Since melanoidins have attracted huge interest as a result of claims for potential health benefits, antioxidant activity and sources of dietary fiber, this investigation aims to elucidate the extraction behavior of melanoidins and their populations during the preparation of portioned espresso coffee. In addition, the antioxidant capacity related to the melanoidins extraction, browning and CGA content is also investigated. 


\section{MATERIALS AND METHODS}

\section{Materials}

Four portioned coffee samples were supplied by three Spanish coffee companies. Single-dose samples were freshly produced, commercially available and identified as gourmet coffees roasted under light medium conditions. Sample F was filter-paper pods hermetically sealed between a two fine layers of filter paper and individually packaged in a protected atmosphere. Sample B was FAP capsule packaged into a biodegradable plastic capsule in a protected atmosphere, which preserves the quality of the ground coffee by protecting it against moisture and oxidation processes. Samples NC and NB were clone capsules closed with aluminum foil (Nespresso $\AA$ compatible). Pure Arabica coffee (Coffea arabica) from Colombia was used for samples $F$, B, and NC. An Arabica and Robusta coffee (Coffea canephora) blend from Vietnam, Guatemala, and Brazil at percentage 35:65 was used for sample NB. Samples were stored at $12-16{ }^{\circ} \mathrm{C}$ and kept I h at ambient temperature before use. According to the coffee companies, the grinding grade of the samples was the most adequate to each type of container and coffee machine. Technical characteristics of the espresso coffeemakers, containers, and coffee are summarized in Table I.

\section{Preparation of coffee brew}

Extraction was performed with three commercial espresso coffee machines and customized to filter-paper pods (F), FAP capsules (B), and clone capsules (N) as described in Table I. Mineral water (Solan de Cabras, Cuenca, Spain) was used with next characteristics (mg/L); 260 dry matter, 284 bicarbonate, 5.I sodium, I.I potassium, 7.4 chloride, 21.3 sulfate, 59.4 calcium, and 7.2 silica. Coffee brew fractions FI, F2, F3, and F4 were collected with final volumes of $5,9,16$, and $46 \mathrm{~mL}$ for coffee samples F, B, NC, and NB. Samples were collected in marked containers for volume. In addition, a fifth fraction of $115 \mathrm{~mL}$ was collected for samples $F$ and $\mathrm{B}$, and $85 \mathrm{~mL}$ for coffee samples NB and NC. Coffee machine $\mathrm{N}$ has a preselected volume of $46 \mathrm{~mL}$ for espresso coffee and $96 \mathrm{~mL}$ for Longo coffee. Coffeemakers $\mathrm{F}$ and $\mathrm{B}$ had a variable control of the volume. Accumulative fraction collection (each fraction contains the previous ones plus certain additional volume) was chosen for higher precision than the sequential collection. Fraction F4 and F5 are also identified as conventional espresso coffee and Longo coffee, respectively. Percolation times ranged from 3 to 80 s regarding the espresso machine and fraction collected. The manufacturer instructions for brewing and adequate machine settings, including preheating, were followed before each coffee preparation. At least an average of 10 extractions were performed and pooled for each fraction. Coffee fractions were lyophilized (VirTis Benchtop-6 KB, SP-Scientific, Ipswich, UK) and stored at $-18{ }^{\circ} \mathrm{C}$ until use. In other case, coffee brew was freeze from three different extractions. The temperature profiles $(n=3)$ were registered by digital thermometer (Model HD2 107.I, Delta OHMSRL, Italy) linked to two thermocouples K type $(\varnothing=0.5 \mathrm{~mm})$ located at the exit and at bottom of the cup.

\section{Basic determinations}

$\mathrm{pH}$ was determined using an electronic $\mathrm{pH}$ meter (Schottmodel CG-837,Mainz, Germany). Total solids content in coffee brew and fractions were determined gravimetrically after sample lyophilization of coffee brew. Additionally, total solid content in fraction F4 and F5was calculated by oven drying $25 \mathrm{~mL}$ of coffee brew at $105^{\circ} \mathrm{C}$ until constant weight $(18 \mathrm{~h})$. The rate of extraction was defined as the percentage of total solids with respect to ground roasted coffee dosage in the container. The maximum rate of extraction in pods and capsules was calculated after manually withdrawing of ground coffee in the container $(n=5)$ and manually extracting the ground coffee $(7 \mathrm{~g})$ with $100 \mathrm{~mL}$ of water at $80{ }^{\circ} \mathrm{C}$ under stirring for $5 \mathrm{~min}$. The resulting coffee brew was filtered (Whatman Filter Paper no 40, Whatman, U.K.), cooled-down, and oven dried. Results are expressed as gram of solids extracted per $100 \mathrm{~g}$ of coffee. Concentration was defined as 
the ratio between total solid content and the volume of the coffee brew. The total carbohydrate content, calculated as the sum of anhydro sugars, was determined using the phenol-sulfuric acid method as described by Dubois, Gilles, Hamilton, Rebers, and Smith (1956). Standard calibration curves were obtained using mannose and arabinose, respectively.

\section{Determination of chlorogenic acids and caffeine}

Caffeine and total chlorogenic acids (CGA) were determined according the method described by Farah et al. (2005) and Fujioka and Shibamoto (2008). One milliliter of coffee brew was mixed with $7 \mathrm{~mL}$ of a $40 \%$ methanolic solution. After treatment with Carrez-I and Carrez-II solutions, supernatant was filtered through a $0.45 \mu \mathrm{m}$ filter and the samples were then analyzed with HPLC. Quantification was conducted with a Shimadzu HPLC system (Kyoto, Japan) equipped with an LC-20 AD pump, an SIL-IOADvp autosampler, a CTO-IOASVP oven, and an SPD-M20A diodearray detector. The chromatographic separation was carried out on a Mediterranean Sea ODS-2 column $(250 \times 4.0 \mathrm{~mm}, 5 \mu \mathrm{m}$, Tecknokroma, Barcelona, Spain). The flow rate was $1.0 \mathrm{~mL} / \mathrm{min}$, and the injection volume was $10 \mu \mathrm{L}$. The mobile phase consisted of $0.5 \%$ acetic acid in water $(\mathrm{v} / \mathrm{v})$ (solvent $A$ ) and methanol (solvent $B$ ), and the gradient program was as follows: 0 min, I5\% B; $3 \mathrm{~min}, 15 \%$ B; $35 \mathrm{~min}, 35 \% \mathrm{~B} ; 40 \mathrm{~min}, 60 \% \mathrm{~B} ; 48 \mathrm{~min}, 80 \% \mathrm{~B} ; 50 \mathrm{~min}, 15 \% \mathrm{~B}$; and $60 \mathrm{~min}, 15 \% \mathrm{~B}$. The total running time was $60 \mathrm{~min}$, and chromatograms were further analyzed at $276 \mathrm{~nm}$ (for caffeine determination) and $325 \mathrm{~nm}$ (for CGA determination). CGAs content in coffee was determined as the sum of caffeoylquinic acids, feruoylquinic acids, and dicaffeoylquinic acids by using 5 -caffeoylquinic acid as an external standard for calibration. The limit of quantification was set at $45.5 \mathrm{mg} / 100 \mathrm{~mL}$ and $4.1 \mathrm{mg} / 100 \mathrm{~mL}$ for caffeine and CGA analysis, respectively.

\section{Determination of browning}

Coffee brew fractions $(1 \mathrm{~mL})$ were diluted 20 -fold with water and $200 \mu \mathrm{L}$ placed in a 96 -wells plate. Browning at $420 \mathrm{~nm}$ was rapidly measured at room temperature using a BioTek SynergyTM HT-multimode microplate spectrophotometer (BioTek Instruments, Winooski, VT, USA).

\section{Determination of antioxidant activity}

The antioxidant activity was estimated in terms of ABTS radical scavenging activity as described by DelgadoAndrade et al. (2005). Briefly, ABTS radical was produced by reacting $7 \mathrm{mM}$ ABTS stock solution with 2.45 $\mathrm{mM}$ potassium persulfate and allowing the mixture to stand in the dark at room temperature for $12-16 \mathrm{~h}$ before use. Coffee brew fractions and melanoidins fractions were properly diluted in water, and $40 \mu \mathrm{L}$ of the diluted samples $(n=4)$ was added with $200 \mu \mathrm{L}$ of water and $60 \mu \mathrm{L}$ of ABTS solution at $37^{\circ} \mathrm{C}$ in dark. Water was used as blank. Absorbance at $734 \mathrm{~nm}$ was taken after $10 \mathrm{~min}$ using a BioTek SynergyTM HTmultimode microplate spectrophotometer (BioTek Instruments, Winooski, VT, USA). Trolox (16 to 500 $\mu \mathrm{mol} / \mathrm{L}$ was used for calibration and results were expressed as $\mu \mathrm{mol}$ Trolox equivalent antioxidant capacity (TEAC) /L of coffee brew or $\mu \mathrm{mol}$ TEAC/g of coffee.

\section{Determination of coffee melanoidin content by spectrophotometry}

Melanoidins from fractions FI, F2, F3, F4, and F5 were obtained after ultrafiltration (10 kDa cutoff) as described by Delgado-Andrade and Morales (2005). Coffee fractions were diluted to a solid content between 0.8 and $1.7 \mathrm{mg} / \mathrm{mL}$. Then samples were subjected to ultrafiltration using a MicroconYM- 10 regenerated cellulose $10 \mathrm{kDa}$ (Millipore, Bedford, MA) at $12000 \mathrm{~g}$ for $10 \mathrm{~min}$. The retentate containing the high molecular weight (HMW) material, corresponding to coffee melanoidins, were recovered by inverting the Microcon device and centrifuged at $1000 \mathrm{~g}$ for $10 \mathrm{~min}$. Finally, the retentate was dissolved in $0.45 \mathrm{~mL}$ of distilled water and measured at $405 \mathrm{~nm}$ as described by Bekedam, Schols, Van Boekel, and Smit (2006) but 
adapted to a microplate reader (Synergy-HT, BioTEK Instruments, Winooski, VT, USA). Coffee melanoidins were quantified using the external standard method within the range of $0.1-1 \mathrm{mg} / \mathrm{mL}$ with a reference coffee melanoidin. Reference coffee melanoidin was prepared from medium roasted coffee beans (C. arabica) as described elsewhere (Silván et al., 2010). Sample reporting levels outside the calibration range were additionally diluted 10 -fold. Melanoidins content $(n=3)$ was expressed as $\mathrm{mg} / \mathrm{mL}$ coffee brew fraction or $\mathrm{mg} / \mathrm{g}$ ground coffee.

\section{Fractionation and isolation of melanoidin populations}

Melanoidins corresponding to the highmolecular weight (HMW) material of espresso coffee were isolated from coffee fractions $\mathrm{FI}, \mathrm{F} 3$, and F4 of coffee sample $\mathrm{F}$ based on the procedure described by DelgadoAndrade and Morales (2005). Lyophilized coffee fractions ( $1 \mathrm{~g})$ were dissolved in $200 \mathrm{~mL}$ of water and ultrafiltrated using an Amicon ultrafiltration cell (Model 8400, Amicon, Veverly, MA, USA) with a nominal molecular weight cutoff of $10 \mathrm{kDa}$. The retentate corresponding to melanoidins was filled to $200 \mathrm{~mL}$ with water and ultrafiltered again at least three times, and then retentate (approximately $50 \mathrm{~mL}$ ) was freeze-dried and stored. The HMW material was separated into four fractions (Wl, Et50, Et75, and Sn75) according to the procedure described by Nunes and Coimbra (2007). Galactomannans and melanogalactomannans can be obtained by precipitation in $50 \%$ ethanol solutions (Et50), arabinogalactans, and melanoarabinogalactans can be obtained by precipitation in $75 \%$ ethanol solutions (Et75), and a second melanoarabinogalactan fraction and the melanoidins of low complexity in carbohydrates remain soluble in $75 \%$ ethanol solutions (EtSn). Freeze-dried HMW material $\left(300 \mathrm{mg}\right.$ ) was dissolved in $20 \mathrm{~mL}$ of water and kept at $4{ }^{\circ} \mathrm{C}$ for $\mathrm{I} \mathrm{h}$. The residue (WI) was removed by centrifugation $\left(5000 \mathrm{rpm}, 10 \mathrm{~min}, 4^{\circ} \mathrm{C}\right)$. The supernatant was added drop wise with $20 \mathrm{~mL}$ of absolute ethanol during 15 min of constant stirring. The resulting solution containing $50 \%$ ethanol was kept at $4{ }^{\circ} \mathrm{C}$ for I h. The residue (Et50) was removed by centrifugation. The supernatant was extended with absolute ethanol to reach a $75 \%$ ethanolic solution. The residue (Et75) was removed by centrifugation (5000 rpm, $10 \mathrm{~min}, 4{ }^{\circ} \mathrm{C}$ ), and the supernatant (Sn75) was separated. Ethanol was removed by flushing nitrogen and rotary evaporation at $40^{\circ} \mathrm{C}$, and then samples were lyophilized and the yield was calculated.

\section{Curve fitting and parameter estimation}

SigmaPlot 12.5 (Systat Software, Chicago, IL) was used to fit 2-parameter hyperbolic single rectangular curves to describe the in-cup extraction kinetics of each coffee constituent. Data were adjusted to $f(y)=a$. $x /(b+x)$. Data set at zero was also included considering an extraction rate of 0 for $0 \mathrm{~mL}$. Graphs were constructed from 2000 iterations. Reduced chi-square was used to compute standards error in weighted regression. Shapiro-Wilk test was used for normality test at a significance level 0.05 . Parameters V50, V95, and Vmax meant the milliliters necessary to reach the $50 \%, 95 \%$, and maximum rate of the parameter measured (melanoidins, browning, antioxidant activity, and total CGA content) as normalized to fraction F5. Additionally, results for $46 \mathrm{~mL}$ of extraction volume corresponding to fraction $\mathrm{F} 4$ are also calculated from the non-linear regression model. Representations were normalized to fraction F5 (large coffee brew) for comparison purposes. Statistical analyses were performed using the Statgraphics Centurion XV statistical program (Herndon, VA). Data were expressed as the mean value \pm SD. Analysis of variance (ANOVA) and the Duncan test were applied to determine differences between means. Differences were considered to be significant at $\mathrm{p} b 0.05$.

\section{RESULTS AND DISCUSSION}

\section{Description of coffeemakers, single-dose units, and ground coffee}

Nowadays, there are many devices and methods to produce espresso coffee, although the use of single-dose units (pods and capsule systems) is growing among consumers and gaining market share because they are 
user-friendly. The overall quality of a cup of coffee depends on the raw material but also on the extractability of a myriad of volatile and non-volatile compounds that makes the taste unique (Petracco, 2005). It is well known that percolation is a very complex phenomenon to model but it depends on the ground coffee portion, particle size distribution, cake porosity, cake shape, water quality, temperature, pressure, percolation time, cake moistening, machine cleanliness, etc. (Parenti et al., 20I4; Petracco, 2005).

In this investigation, three commercial available espresso coffeemakers for single-dose units were selected and their technical characteristics are described in Table I. Three samples ( $F, B$, and NC) were from the coffee specie most commercialized worldwide C. arabica. Sample NB is a coffee commercial product that consists of blend of C. Arabica and C. canephora. Espresso coffeemakers have common features such as the application of constant pressure that forces water through the coffee grounds with a constant flow. The filter-paper pods (sample F) used for machine $F$ has the largest contact area and lower extraction flow as compared with FAP capsules (sample B) used in machine B or clone capsules (samples NC, and NB) used in machine $N$. The espresso coffeemaker using the capsules with a clone format has the highest ratio water/coffee for an espresso coffee $(46 \mathrm{~mL})$, followed by filter-paper pods, and FAP capsules. Clone capsules have the lowest ground coffee content but the highest ratio water to coffee. The maximum extraction rate was not significantly different among the samples, and it reached an average about $27 \%$ (Table I). This fact is important since the final extraction rate obtained at fraction F5 will be due to the efficacy of each coffeemaker and the type of single-dose container.

Ground coffee was partly characterized for the total carbohydrate, caffeine, CGA, and melanoidin content as summarized in Table 2. Total carbohydrate content (expressed as mannose equivalents), caffeine, and total CGA ranged from 33 to $46 \mathrm{~g} / \mathrm{l} 00 \mathrm{~g}$, from 1.1 to $1.8 \mathrm{~g} / 100 \mathrm{~g}$, and from 0.79 to $1.6 \mathrm{~g} / 100 \mathrm{~g}$, respectively. Carbohydrates, caffeine, and CGA contents are in line with literature (Farah, 2012). As expected higher content of CGA, carbohydrates and caffeine was obtained in the Arabica/Robusta blend (sample NB) as compared with Arabica (sample NC). Sample F showed the higher melanoidin content ( $1 \mathrm{lg} / 100 \mathrm{~g}$ coffee) as compared to capsules (about $7.5 \mathrm{~g} / 100 \mathrm{~g}$ coffee). All the samples showed a melanoidin content close to mild roasting conditions where their formation is still low (Silván et al., 2010).

It is well known that the concentration of coffee constituents in the brew is affected by the type and origin of ground coffee, roasting degree, and brewing procedure (Andueza et al., 2003; Petracco, 2005). Extraction for pods and capsules was further investigated by applying an accumulative fractionation approach during the brewing process as described by Mestdagh et al. (20l4). Five consecutive different fractions were collected. For instance, fraction F3 contains fraction F2 plus and additional volume. Fig. I describes the temperaturevolume profile for the three espresso coffeemakers using filter-paper pods, FAP capsules and clone capsules. Dotted lines represent the volume of the five fractions collected. Coffee brew volume for fractions FI, F2, F3, and F4 (corresponding to espresso coffee) was the same for all samples. However, fraction F5 (corresponding to Longo coffee) was $115 \mathrm{~mL}$ for pods and FAP capsules and $85 \mathrm{~mL}$ for sample clone capsules. Traditionally, espresso coffee is brewed in short volumes $(20 \mathrm{~mL}$ to $50 \mathrm{~mL})$, and Longo is a less intense beverage characterized by a larger cup size (100 mL up to $250 \mathrm{~mL}$ ), where size depends on culture habits, lifestyle, social and working environment, everyday habits and financial considerations, and flavor preference (Parenti et al., 20I4; Petracco, 2005). Percolation time for fraction F5 was 80 s, 70 s for pods and FAP capsules, and $44 \mathrm{~s}$ for clone capsules. The lowest extraction flow was for coffeemaker for pods with 1.5 $\mathrm{mL} / \mathrm{s}$ (Table I). The temperature at the exit was $87.13^{\circ} \mathrm{C} \pm 5.83,85.6{ }^{\circ} \mathrm{C} \pm 0.35$, and $90.85{ }^{\circ} \mathrm{C} \pm 0.92$ for coffeemakers $\mathrm{F}, \mathrm{B}$, and $\mathrm{N}$, respectively. Thermal profiles were registered during the extraction process. 
After a phase of instability at the beginning, temperatures stayed around a mean temperature (Albanese et al., 2009).

\section{Extraction rate}

It is expected that the extraction efficiency of the coffee constituents was driven by their solubility in water (Gloess et al., 2013; Parenti et al., 2014; Petracco, 2005). Higher volume of water during extraction, as for Longo coffee in fraction F5, should lead to higher extraction efficiency (Ludwig et al., 2012; Mestdagh et al., 20I4; Parenti et al., 20I4). The extraction rate for each coffeemaker and single-dose container is depicted in Fig. 2. Extraction rate increases very rapidly in all samples with the extraction volume although conditions for the espresso coffee (fraction F4) are already close to the maximum rate achieved in Longo coffee (fraction F5). After that, an increment in the percolation time did not reflect a significant increment in the extraction rate. It is noteworthy that each sample reached a different final extraction rate varying from $20.4 \%$ to $27.1 \%$. If compared the final extraction rate with the maximum extraction rate described in Table I, single-dose pod behaved very efficiently since nearly $100 \%$ of the maximum extraction rate was reached. The lowest extraction rates were obtained for B, NC, and NB samples, $78.5 \%, 93.5 \%$, and $85 \%$, respectively, as compared with the maximum extractability. In terms of solids content, fraction F5 contains $16.2 \pm 0.42$, $13.9 \pm 1.58,15.1 \pm 1.00$, and $14.2 \pm 0.53 \mathrm{mg} / \mathrm{mL}$ of coffee brew for $\mathrm{F}, \mathrm{B}, \mathrm{NC}$, and NB, respectively. For comparative purposes, data for density, $\mathrm{pH}$, and concentration of fraction $\mathrm{F} 4$ (espresso coffee) is summarized in Table I.

Different coffeemakers, single-dose units (pods, and capsule), and ground coffee with different origin and likely roasting degree are used in this investigation. There are many physical parameters governing the extraction such as temperature inside the cake, the pressure above and under the cake, percolation time, dose, particle size and shape, compacting of the bed, etc (Albanese et al., 2009; Andueza et al., 2002; Andueza et al., 2003; Illy \& Viani, 2005; Petracco, 2005). Table 2 summarizes the chemical characterization of fraction $\mathrm{F} 5$ for samples $\mathrm{F}, \mathrm{B}, \mathrm{NB}$, and NC in terms of total carbohydrate, caffeine, CGA, melanoidins, total solids content, browning, and antioxidant capacity. Since every sample has a different composition, it is not reliable a direct comparison among samples without a normalization of the process. The kinetic for the extraction was normalized to fraction F5 (corresponding to Longo coffee) since it contains every previous fractions.

\section{Extractability of melanoidins}

The kinetic of the melanoidins extraction for sample F, B, and NC is depicted in Fig. 3a. The extraction profile for NB (arabica:robusta blend) is not displayed to maintain clearer the graphical representation. Table 3 summarizes the parameters and adjustment of the fit, including calculation of the extraction volume necessary to reach the 50\% (V50), 90\% (V90), and maximum (Vmax) melanoidin content. The extractability of the melanoidins behaves significantly different according to the type of single-dose unit used. Melanoidins were efficiently extracted in NC samples since less than $9 \mathrm{~s}$ was necessary to extract the $50 \%$ of the melanoidin content. In contrast, melanoidins in sample B were slowly extracted during brewing, and $18 \mathrm{~s}$ was necessary to reach the $50 \%$ of the melanoidin content in fraction F5. Extrapolating the model for espresso coffee (fraction F4, $46 \mathrm{~mL}$ ), coffee brewed from clone capsules allows significantly a faster extraction of melanoidins ( $94.3 \%$ of the total) than filter-paper pods $(84.8 \%$ ) and FAP capsules $(77.4 \%)$, regardless the initial melanoidin content in the Arabica ground coffee.

Melanoidins are defined as polymeric brown-color material. Indeed, previous investigation used the browning rate as an approximation of the melanoidin content (Ludwig et al., 2012). Browning during the 
brewing of coffee from pods and capsules was also modeled. Fig. 3b depicts the browning of the different coffee fractions and the model is normalized to fraction $F 5$. In contrast to the melanoidins profile, sample $F$ and $B$ did not show significant differences during the extraction. However, the extractability of brown colored compounds in fraction F4 was significantly higher for sample NC $(93.8 \%)$ as compared with samples $\mathrm{F}(81.8 \%)$ and $\mathrm{B}(82.2 \%)$ (Table 3).

\section{Extractability of browning rate, antioxidant compounds and CGA}

Coffee melanoidins have different functional properties apart from their contribution to color and technological properties, being able to bind flavors, exerting antioxidant capacity to foods and suppressing oxidative stress in cells, metal-chelating properties, antimicrobial activity, antihypertensive, suppressing Helicobacter pylori adhesion, modulating chemopreventive enzymes, and prebiotic activity, among others (Fogliano \& Morales, 20II; Wang et al., 20II). Perhaps the most relevant characteristic of coffee melanoidins is their antioxidant capacity. Literature suggests that the main compounds responsible for the antioxidant activity in roasted coffee are several phenolic compounds naturally present in green coffee beans and Maillard reaction products formed in the roasting process (Borrelli et al., 2002; Farah \& Donangelo, 2006). Antioxidant capacity of the fractions collected during coffee brewing was investigated as depicted in Fig. 3c, and adjustment of the fit is described in Table 3. Again, espresso coffeemakers using clone capsules extracted significantly faster the compounds accounting to the overall antioxidant capacity than filter-paper pods and FAP capsules. Nearly $90 \%$ of the total antioxidant capacity of coffee brew in fraction F4was already extracted in clone capsules, $83 \%$ for filter-paper pods, and $79 \%$ for FAP capsules.

Despite to melanoidins and low molecular weight (LMW) Maillard reaction products, CGA are the main contributor to the antioxidant capacity of the coffee brew. Fig. 3d depicts the extraction kinetics for CGA and parameters for the fit are summarized in Table 3. Both filter paper pods and clone capsules extracted very efficiently (N90\% from the total) the CGA in espresso coffee. There is no significant differences in the extraction profile for filter-paper pods and clone capsules ( $\mathrm{N} 94 \%$ ), but significant lower extraction rate was reached for FAP capsules (87\%) in espresso coffee.

According to literature, CGA are considered to be the major contributors to the antioxidant capacity of coffee brew, followed by melanoidins, and the LMW compounds formed during coffee roasting (Daglia et al., 2000; Delgado-Andrade et al., 2005; Vignoli, Bassoli, \& Benassi, 20II). Ludwig et al. (2012) described that espresso machine increases extraction speed of browning and antioxidants in coffee brew as compared with filter coffee. Fig. 4 depicts the relationship between the antioxidant capacity for each single-dose unit and browning rate, melanoidins, solids, and CGA content. The extraction profile of all these parameters are directly related to the antioxidant capacity in each fraction. However, extraction profile of melanoidins and browning fitted better with the antioxidant capacity for all the fractions than CGA and total solids profile. These results are in line with Coelho et al. (2014), who found a significant correlation between the amount of phenolic compounds incorporated to melanoidins and the amount of protein and color characteristics of the different melanoidin populations being observed. In fractions FI, F2, or F3 for pods (Fig. 4a), FAP capsule (Fig. 4b), and clone capsules with blend (Fig. 4d), the higher extraction of CGA and total solids did not reflect a significant increment in the antioxidant capacity.

\section{Extractability and antioxidant capacity of melanoidin populations}

The contribution of the different populations of melanoidins to the total antioxidant capacity of coffee brew and their kinetic of extraction was further investigated in filter-paper pods. The HMW material of coffee brew is composed by a mixture of thermally transformed galactomannans and arabinogalactans and by a 
diversity of melanoidin populations presenting different physical properties and chemical composition (Moreira et al., 2012). Fractions FI, F3, and F4 of pods were included in the investigation. The total solids content in fractions $\mathrm{FI}, \mathrm{F} 3$, and $\mathrm{F} 4$ were $109.9,80.7$, and $38.2 \mathrm{mg} / \mathrm{mL}$, respectively. After cell stirring ultrafiltration with a membrane cutoff of $10 \mathrm{kDa}$, the content in $\mathrm{HMW}$ material correspond to 33.7, 23.0, and $12.4 \mathrm{mg} / \mathrm{mL}$ for fraction $\mathrm{FI}, \mathrm{F} 3$, and $\mathrm{F} 4$, respectively. It is noteworthy to highlight that this result matched with the calculation of melanoidin content reported above by using the spectrophotometric method. HMW material was further fractionated according to solubility in ethanol as described by Nunes and

Coimbra (2007). Four fractions were obtained corresponding to the water insoluble fraction (WI), insoluble at ethanol 50\% (Et50), insoluble at ethanol 75\% (Et75), and soluble at ethanol 75\% (Sn75). The average proportions of each population of melanoidins were 10\% (8.1-12.3), 27\% (25.5-31.5), 15\% (10.2-16.4), and 48\% (47.5-50.4) for fractions WI, Et50, Et75, and Sn75, respectively. The predominant population of melanoidins in all the coffee fractions was Sn75 that accounted for nearly 50\% of the total HMW material in weight. These results are in line with Coelho et al. (2014), who reported an HMW material content of 3.73 $\mathrm{g} / 100 \mathrm{~g}$ in filter coffee (total soluble solids contents of $14.9 \mathrm{~g} / 100 \mathrm{~g}$ of coffee), whereas $32.7 \%, 16.8$, and $50.5 \%$ correspond to the fractions Et50, Et75, and Sn75. The melanoidin population soluble in ethanol contained the majority of the phenolic compounds incorporated into the HMW material during roasting by either ester linkages or condensed forms (non-ester covalent linkages (Delgado-Andrade \& Morales, 2005; Bekedam et al., 2008; Nunes, Cruz, \& Coimbra, 2012; Perrone, Farah, \& Donangelo, 2012).

Literature describes that melanoidins accounted for $26-38 \%$ of the overall antioxidant capacity the coffee brew, depending on the assay applied (Perrone et al., 2012; Rufián-Henares \& Morales, 2007). Fig. 5 describes the antioxidant capacity of the HMW material and LMW material isolated from fractions FI, F3, and F4. Results are expressed per gram of sample to allow the direct comparison between activities of the fractions. Regardless the fraction investigated, the antioxidant capacity of melanoidins was always higher than their respective LMW weight material in terms of absolute value of mass. In other words, same amount of HMW material exerted higher antioxidant capacity of the LMW fraction. However, it is important to keep in mind that content of LMW material in coffee brew is higher, nearly $70 \%$, than the HMW material, as described above. There were not significant differences in the contribution of melanoidins to the antioxidant capacity in fractions FI, F3, and F4. However, LMW material extracted in fraction FI had significantly higher antioxidant capacity than those extracted in fractions F3 and F4. This result is expected since CGA is extracted faster than melanoidins and browning rate (Table 3). In the first $68.3 \mathrm{~mL}$, all the CGA is extracted, but more than $100 \mathrm{~mL}$ is necessary to extract all the melanoidins and browning. Results also showed that melanoidin population Sn75 had the highest antioxidant capacity as compared with Et50 and Et75, which could be explained by the higher presence of phenolic compounds linked to their structure and lower carbohydrate complexity (Coelho et al., 2014).

Many investigations pointed out that melanoidins may have beneficial in vivo effects, such as antioxidant activity, and phase I and phase II enzyme-modulating activity, including to be beneficial to human health, displaying in vivo antioxidant, antimicrobial, and prebiotic activity in the intestine because certain melanoidin populations behaves as an antioxidant indigestible fiber (Borrelli et al., 2004; Daglia et al., 2000; Morales et al., 2012; Reichardt et al., 2009; Silván et al., 2010; Wang et al., 201I). However, melanoidins have also technological effects since their presence is directly associated with the reduction of the intensity of the sulfury-roasty odor quality of the coffee brew (Hofmann et al., 200I). To better implement the health benefits of melanoidins to consumers, it is necessary to understand their kinetic of extraction during 
preparation of coffee brew. This investigation will allow the optimization of the espresso coffeemakers to enhance the proper extraction of melanoidins in the cup.

\section{CONCLUSIONS}

This investigation pointed out that the type of portioned coffee and espresso coffeemaker is critical for the extractability of melanoidins regardless the coffee origin. Melanoidins are rapidly extracted ere nearly $50 \%$ is already extracted within first $20 \mathrm{~mL}$ regardless the type of single dose unit used. However, the efficacy of the melanoidins extraction was higher in clone capsules, as compared with pods and lately to FAP capsules. In addition, no significant differences were observed in the extractability of the populations of melanoidins for espresso coffee with pods, accounting for nearly the 10\%, 27\%, 15\%, and $48 \%$ of the total melanoidin content for fraction WI, Et50, Et75, and Sn75, respectively. However, the antioxidant capacity of the melanoidin populations increases with the extraction volume, and their structure is very likely not the same since their antioxidant activity is different. Melanoidin population related to Sn75 showed the highest antioxidant activity and increased significantly from fraction $\mathrm{FI}$ to fraction $\mathrm{F} 3$ or $\mathrm{F} 4$. It could be plausible that more complex phenolic-rich structures with higher antioxidant capacity need longer extraction volumes. This statement should be confirmed with further experiments that involves chemical characterization of the melanoidin populations. In addition, extraction kinetics of browning, antioxidant capacity, and melanoidins are not always correlated, and it will likely depend on the type of the ground coffee and roasting conditions. Investigation on the extractability of melanoidins could make possible the adjustment of the technological requirements of coffee machines and extraction techniques to produce a coffee with high levels of beneficial compounds.

\section{CONFLICT OF INTEREST}

The authors have no conflict of interest.

\section{ACKNOWLEDGMENT}

Authors thank to Spanish coffee companies Fortaleza, ElAbra, and Mocay for technical guidance. This research is partly funded by the Spanish National Research Council under project CSIC-201370E027 and the Autonomous Community of Madrid under project SI0I3/ABI-3028-AVANSECAL (CAM). C. Bartel is grateful to an Erasmus program grant from the Erlangen-Nuremberg University.

\section{REFERENCES}

Albanese, D., DiMatteo, M., Poiana, M., \& Spagnamusso, S. (2009). Espresso coffee (EC) by POD: Study of thermal profile during extraction process and influence of water temperature on chemical-physical and sensorial properties. Food Research International, 42, 727-732.

Andueza, S., de Peña, M.P., \& Cid, C. (2003). Chemical and sensorial characteristics of espresso coffee as affected by grinding and torrefacto roast. Journal of Agricultural and Food Chemistry, 5I, 7034-7039.

Andueza, S.,Maeztu, L., Dean, B., de Peña, M.P., Bello, J., \& Cid, C. (2002). Influence of water pressure on the final quality of Arabica espresso coffee. Application of multivariate analysis. Journal Agricultural and Food Chemistry, 50, 7426-743I.

Bekedam, E.K., Schols, H.A., Van Boekel, M., \& Smit, G. (2006). High molecular weight melanoidins from coffee brew. Journal of Agricultural and Food Chemistry, 54, 7658-7666.

Bekedam, E.K., Schols, H.A., van Boekel, M.A., \& Smit, G. (2008). Incorporation of chlorogenic acids in coffee brew melanoidins. Journal of Agriculture and Food Chemistry, 56, 2055-2063.

Bichler, J., Cavin, C., Simic, T., Chakraborty, A., Ferk, F., Hoelzl, C., et al. (2007). Coffee consumption protects human lymphocytes against oxidative and 3-amino-I-methyl-5Hpyrido[4,3-b] indoleacetate (Trp-P- 
2) induced DNA-demage: Results of an experimental study with human volunteers. Food and Chemical Toxicology, 45, 1428-1436.

Borrelli, R.C., Esposito, F., Napolitano, A., Ritieni, A., \& Fogliano, V. (2004). Characterization of a New potential functional ingredient: Coffee silverskin. Journal of Agricultural and Food Chemistry, 52, I338-1343. Borrelli, R.C., Visconti, A., Mennella, C., Anese, M., \& Fogliano, V. (2002). Chemical characterization and antioxidant properties of coffee melanoidins. Journal of Agriculture and Food Chemistry, 50, 6527-6533.

Cavin, C., Marin-Kuan, M., Langouët, S., Bezencon, C., Guignard, G., Verguet, C., et al. (2008). Induction of Nrf2-mediated cellular defenses and alteration of phase I activities as mechanisms of chemo protective effects of coffee in the liver. Food and Chemical Toxicology, 46, I239-1248.

Coelho, C., Ribeiro, M., Cruz, A.C.S., Domingues, M.R.M., Coimbra, M.A., Bunzel, M., et al. (2014). Nature of phenolic compounds in coffee melanoidins. Journal of Agricultural and Food Chemistry, 62, 7843-7853.

Daglia, M., Papetti, A., Gregotti, C., Bertè, F., \& Gazzani, G. (2000). In vitro antioxidant and ex vivo protective activities of green and roasted coffee. Journal of Agricultural and Food Chemistry, 48, 1449-I454. Delgado-Andrade, C., \& Morales, F.J. (2005). Unraveling the contribution of melanoidins to the antioxidant activity of coffee brews. Journal of Agricultural and Food Chemistry, 53, I403-1407.

Delgado-Andrade, C., Rufián-Henares, J.A., \& Morales, F.J. (2005). Assessing the antioxidant activity of melanoidins from coffee brews by different antioxidant methods. Journal of Agricultural and Food Chemistry, 53, 7832-7836.

Díaz-Rubio, M.E., \& Saura-Calixto, F. (2007). Dietary fiber in brewed coffee. Journal of Agricultural and Food Chemistry, 55, 1999-2003.

Dubois, M., Gilles, K.A., Hamilton, J.K., Rebers, P.A., \& Smith, F. (1956). Colorimetric method for determination of sugars and related substances. Analytical Chemistry, 28, 350-356.

Esposito, F., Verde, V., Alezio, A., Ritieni, A., Morisco, F., Caporaso, N., et al. (2003). Coffee consumption increases plasma glutathione and not homocysteine in healthy volunteers. Alimentary Pharmacology and Therapeutics, 17, 595-60I.

Farah, A. (2012). Coffee Constituents. In Y.F. Chu (Ed.), Coffee. Emerging health effects and disease prevention (Pp. 2I-58). lowa, USA: John Wiley \& Sons and Institute of Food Technologists.

Farah, A., de Paulis, T., Trugo, L.C., \& Martin, P.R. (2005). Effect of roasting on the formation of chlorogenic acid lactones in coffee. Journal of Agricultural and Food Chemistry, 53, 1505-1513.

Farah, A., \& Donangelo, C.M. (2006). Phenolic compounds in coffee. Brazilian Journal of Plant Physiology, I8, 23-36.

Fogliano, V., \& Morales, F.J. (20I I). Estimation of dietary intake of melanoidins from coffee and bread. Food \& Function, 2, 117-123.

Fujioka, K., \& Shibamoto, T. (2008). Chlorogenic acids and caffeine content in various brewed coffees. Food Chemistry, 106, 217-221.

Garsetti,M., Pellegrini, N., Baggio, C., \& Brighenti, F. (2000). Antioxidant activity in human faeces. British Journal of Nutrition, 84, 705-710.

Gloess, A., Schönbächler, B., Klopprogge, B., D`Ambrosio, L., Chatelain, K., Bongartz, A., et al. (2013). Comparison of nine common coffee extraction methods: Instrumental and sensory analysis. European Food Research and Technology, 236, 607-627.

Hofmann, T., Czerny, M., Calligaris, S., \& Schieberle, P. (2001). Model studies on the influence of coffee melanoidins on flavor volatiles of coffee beverages. Journal of Agricultural and Food Chemistry, 49, 23822386.

Illy, A., \& Viani, R. (2005). Espresso Coffee. The science of quality (2nd ed.). London, UK: Elsevier Academic Press. 
Lindsay, J., Laurin, D., Verreault, R., Hébert, R., Helliwell, B., Hill, G.B., et al. (2002). Risk factors for Alzheimer's disease: A prospective analysis fromthe Canadian study of health and aging. American Journal of Epidemiology, 156, 445-453.

López-Galilea, I., de Peña, M., \& Cid, C. (2007). Correlation of selected constituents with the total antioxidant capacity of coffee beverages: Influence of the brewing procedure. Journal of Agricultural and Food Chemistry, 55, 6110-6117.

López-Galilea, I., Fournier, N., Cid, C., \& Guichard, E. (2006). Changes in headspace volatile concentrations of coffee brews caused by the roasting process and the brewing procedure. Journal of Agricultural and Food Chemistry, 54, 8560-8566.

Ludwig, I.A., Sanchez, L., Caemmerer, B., Kroh, L.W., De Peña,M.P., \& Cid, C. (2012). Extraction of coffee antioxidants: Impact of brewing time and method. Food Research International, 48, 57-64.

Maeztu, L., Andueza, S., Ibañez, C., de Peña, M.P., Bello, J., \& Cid, C. (200I). Multivariate methods for characterization and classification of espresso coffees from different botanical varieties and types of roast by foam, taste, and mouthfeel. Journal Agricultural and Food Chemistry, 49, 4743-4747.

Manach, C., Scalbert, A., Morand, C., Rémésy, C., \& Jiménez, J. (2004). Polyphenols: food sources and bioavailability. American Journal of Clinical Nutrition, 79, 727-747.

Mestdagh, F., Davidek, T., Chaumonteuil, M., Folmer, B., \& Blank, I. (20I4). The kinetics of coffee aroma extraction. Food Research International, 63, 27I-274.

Morales, F.J., Somoza, V., \& Fogliano, V. (2012). Physiological relevance of dietary melanoidins. Amino Acids, 42, 1097-1109.

Moreira, A.S.P., Nunes, F.M., Domingues, M.R., \& Coimbra, M.A. (20I2). Coffee melanoidins: structures, mechanisms of formation and potential health impacts. Food \& Function, 3, 903-915.

Nunes, F.M., \& Coimbra, M.A. (2007). Melanoidins from coffee infusions. Fractionation, chemical characterization, and effect of the degree of roast. Journal of Agricultural and Food Chemistry, 55, 39673977.

Nunes, F.M., Cruz, A.C.S., \& Coimbra, M.A. (2012). Insight into the mechanism of coffee melanoidin formation using modified "in bean" models. Journal of Agricultural and Food Chemistry, 60, 8710-87I9.

Parenti, A., Guerrini, L., Masella, P., Spinelli, S., Calamai, L., \& Spugnoli, P. (2014). Comparison of espresso coffee brewing techniques. Journal of Food Engineering, 121, II2-117.

Pastoriza, S., \& Rufián-Henares, J.A. (2014). Contribution of melanoidins to the antioxidant capacity of the Spanish diet. Food Chemistry, 164, 438-445.

Perrone, D., Farah, A., \& Donangelo, C.M. (20I2). Influence of coffee roasting on the incorporation of phenolic compounds into melanoidins and their relationship with antioxidant activity of the brew. Journal of Agricultural and Food Chemistry, 60, 4265-4275.

Petracco, M. (2005). Percolation. In A. Illy, \& R. Viani (Eds.), Espresso coffee: The science of quality (pp. 259289). London, UK: Elsevier Academic Press.

Ranheim, T., \& Halvorsen, B. (2005). Coffee consumption and human health-beneficial or detrimental?Mechanisms for effects of coffee consumption on different risk factors for cardiovascular disease and type 2 diabetes mellitus. Molecular Nutrition and Food Research, 49, 274-284.

Reichardt, N., Gniechwitz, D., Steinhart, H., Bunzel, M., \& Blaut, M. (2009). Characterization of high molecular weight coffee fractions and their fermentation by human intestinal microbiota. Molecular Nutrition and Food Research, 53, 287-299.

Rufián-Henares, J.A., \& Morales, F.J. (2007). Effect of in vitro enzymatic digestion on antioxidant activity of coffee melanoidins and fractions. Journal of Agricultural and Food Chemistry, 55, 10016-10021.

Salazar-Martinez, E., Willett, W.C., Ascherio, A., Manson, J.E., Leitzmann, M.F., Stampfer, M.J., et al. (2004). Coffee consumption and risk for type 2 diabetes mellitus. Annals of Internal Medicine, 140, I-8. 
Silván, J.M., Morales, F.J., \& Saura-Calixto, F. (2010). Conceptual study on maillardized dietary fiber in coffee. Journal of Agricultural and Food Chemistry, 58, 12244-12249.

Torres, T., \& Farah, A. (2010). Coffee is the most important contributor to the antioxidant capacity in Brazilian's diet. FASEB Journal, 24, 919.

Vignoli, J.A., Bassoli, D.G., \& Benassi, M.T. (201 I). Antioxidant activity, polyphenols, caffeine and melanoidins in soluble coffee: The influence of processing conditions and raw material. Food Chemistry, 124, 863-868.

Wang, H.Y., Qian, H., \& Yao,W.R. (201I). Melanoidins produced by the Maillard reaction: Structure and biological activity. Food Chemistry, 128, 573-584. 


\section{FIGURES AND TABLES}

Table I. Identification of samples, description of technical parameters for espresso coffee machines, types of single-dose containers, and characterization of espresso coffee.

\begin{tabular}{|c|c|c|c|c|}
\hline & $F$ & B & NC & NB \\
\hline Coffeemaker & Basic (Ascaso Factory, ES) & Cappuccino (Espressos del Capitano, IT) & Inissia (DeLonghi, HU) & Inissia (DeLonghi, HU) \\
\hline Pressure (bar) & 16 & 20 & 19 & 19 \\
\hline Water reservoir $(\mathrm{mL})$ & 2000 & 1000 & 700 & 700 \\
\hline Extraction flow $(\mathrm{mL} / \mathrm{s})^{*}$ & 5.2 & 3.2 & 6.0 & 6,0 \\
\hline in-cup temp. $\left({ }^{\circ} \mathrm{C}\right)^{*}$ & $68.3 \pm 1.8 \mathrm{a}$ & $77.8 \pm 0.5 b$ & $75.2 \pm 1.2 \mathrm{c}$ & $75.2 \pm 1.2 c$ \\
\hline Coffee container & Filter-paper pod & $\begin{array}{l}\text { Biodegradable polypropylene FAP } \\
\text { capsule }\end{array}$ & $\begin{array}{l}\text { Plastic with aluminum foil clone } \\
\text { capsule }\end{array}$ & $\begin{array}{l}\text { Plastic with aluminum foil clone } \\
\text { capsule }\end{array}$ \\
\hline Container size (mm) & $60 \times 45 \times 10$ & $40 \times 34 \times 20$ & $38 \times 20 \times 25$ & $39 \times 20 \times 25$ \\
\hline Coffee origin & Colombia & Colombia & Colombia & Vietnam, Guatemala, Brazil \\
\hline Coffee blend & Arabica $100 \%$ & Arabica $100 \%$ & Arabica $100 \%$ & Arabica $35 \%$ Robusta $65 \%$ \\
\hline Coffee (g) per container & $6.866 \pm 0.141 \mathrm{~b}$ & $7.853 \pm 0.053 c$ & $5.224 \pm 0.058 a$ & $5.211 \pm 0.027 \mathrm{a}$ \\
\hline Partide size $(\mu \mathrm{m})$ & $200-400$ & $300-800$ & $300-600$ & $300-700$ \\
\hline Extraction flow $(\mathrm{mL} / \mathrm{s})$ & 1.5 & 2.0 & 2.1 & 2.1 \\
\hline In-cup temperature $\left({ }^{\circ} \mathrm{C}\right)$ & $75.0 \pm 2.9 \mathrm{a}$ & $82.7 \pm 4.3 \mathrm{~b}$ & $79.8 \pm 3.0 \mathrm{ab}$ & $79.7 \pm 3.3 \mathrm{ab}$ \\
\hline Max. extraction rate (\%) & $27.8 \pm 0.75 \mathrm{a}$ & $26.3 \pm 0.82 \mathrm{a}$ & $26.7 \pm 1.01 \mathrm{a}$ & $27.9 \pm 0.74 a$ \\
\hline Water/coffee $(\mathrm{mL} / \mathrm{g})^{* * *}$ & 6.7 & 5.9 & 8.8 & 8.8 \\
\hline Density at $20^{\circ} \mathrm{C}(\mathrm{g} / \mathrm{mL})^{* *}$ & $0.941 \pm 0.014 b$ & $1.037 \pm 0.031 c$ & $0.744 \pm 0.027 a$ & $0.705 \pm 0.066 a$ \\
\hline $\mathrm{pH}^{* *}$ & $5.0 \pm 0.1 \mathrm{a}$ & $5.0 \pm 0.3 a$ & $5.0 \pm 0.1 \mathrm{a}$ & $5.2 \pm 0.1 \mathrm{a}$ \\
\hline Concentration (mg/mL) ${ }^{* *}$ & $38.2 \pm 0.28 c$ & $31.1 \pm 0.27 \mathrm{~b}$ & $28.2 \pm 1.75 b$ & $24.6 \pm 0.70 \mathrm{a}$ \\
\hline
\end{tabular}

Different letters in a same row identify significant differences $(p<0.05)$. Data are expressed as mean \pm stand ard deviation. *Extraction without pods or capsule. * Calculated for a volume of $46 \mathrm{~mL}$, corresponding to espresso coffee.

Table 2. Carbohydrate, caffeine, total chlorogenic acids (CGA), melanoidins, total solid content, total solids on filtrate, browning, and antioxidant capacity in ground coffee and their respective fraction F5.

\begin{tabular}{|c|c|c|c|c|}
\hline & $F$ & B & NC & NB \\
\hline \multicolumn{5}{|l|}{ Ground coffee $(\mathrm{g} / 100 \mathrm{~g})$} \\
\hline Carbohydrate (as mannose eq.) & $38.3 \pm 1.0 \mathrm{ab}$ & $33.3 \pm 6.2 \mathrm{a}$ & $39.5 \pm 4.4 a b$ & $46.3 \pm 6.0 \mathrm{~b}$ \\
\hline Carbohydrate (as arabinose eq.) & $27.2 \pm 7.0 \mathrm{ab}$ & $24.0 \pm 0.1 \mathrm{a}$ & $29.0 \pm 7.5 b$ & $34.6 \pm 8.8 b$ \\
\hline Caffeine & $1.15 \pm 0.12 \mathrm{a}$ & $1.10 \pm 0.11 \mathrm{a}$ & $1.17 \pm 0.01 \mathrm{a}$ & $1.76 \pm 0.03 b$ \\
\hline Total CGA & $1.12 \pm 0.15 b$ & $1.18 \pm 0.16 \mathrm{~b}$ & $0.79 \pm 0.09 \mathrm{a}$ & $1.59 \pm 0.33 c$ \\
\hline Melanoidins & $11.0 \pm 1.6 \mathrm{~b}$ & $7.7 \pm 1.0 \mathrm{a}$ & $7.8 \pm 0.1 \mathrm{a}$ & $7.4 \pm 0.2 \mathrm{a}$ \\
\hline \multicolumn{5}{|l|}{ Fraction F5 $(\mathrm{mg} / \mathrm{mL})$} \\
\hline Carbohydrate (as mannose eq.) & $7.3 \pm 1.2 \mathrm{a}$ & $6.8 \pm 0.7 \mathrm{a}$ & $6.1 \pm 0.7 \mathrm{a}$ & $6.2 \pm 1.1 \mathrm{a}$ \\
\hline Carbohydrate (as arabinose eq.) & $5.2 \pm 0.4 b$ & $4.7 \pm 0.8 \mathrm{ab}$ & $4.1 \pm 0.8 \mathrm{a}$ & $4.2 \pm 0.5 \mathrm{a}$ \\
\hline Caffeine & $0.79 \pm 0.16 \mathrm{ab}$ & $0.80 \pm 0.23 \mathrm{ab}$ & $0.77 \pm 0.18 \mathrm{a}$ & $1.08 \pm 0.26 \mathrm{~b}$ \\
\hline Total CGA & $0.72 \pm 0.24 a b$ & $0.85 \pm 0.33 \mathrm{~b}$ & $0.52 \pm 0.19 \mathrm{a}$ & $0.65 \pm 0.20 \mathrm{a}$ \\
\hline Melanoidins & $6.3 \pm 0.7 b$ & $3.8 \pm 0.3 \mathrm{a}$ & $4.9 \pm 0.5 \mathrm{ab}$ & $4.5 \pm 0.2 \mathrm{a}$ \\
\hline Total solid content & $16.2 \pm 0.4 b$ & $13.9 \pm 1.6 \mathrm{a}$ & $15.1 \pm 1.0 \mathrm{ab}$ & $14.2 \pm 0.5 \mathrm{a}$ \\
\hline Total solids on filtrate & $15.3 \pm 0.6 \mathrm{~d}$ & $12.6 \pm 0.1 \mathrm{a}$ & $14.8 \pm 0.3 c$ & $13.6 \pm 0.6 b$ \\
\hline Browning $\left(\mathrm{A}_{405} / \mathrm{mL}\right)$ & $7.6 \pm 0.3 c$ & $5.3 \pm 0.4 a$ & $6.0 \pm 0.4 \mathrm{~b}$ & $5,4 \pm 0.3 \mathrm{ab}$ \\
\hline Antiox. capacity (TEAC mmol/L) & $17.7 \pm 0.1 \mathrm{~b}$ & $15.0 \pm 0.7 \mathrm{a}$ & $15.1 \pm 0.6 \mathrm{a}$ & $17.3 \pm 0.3 b$ \\
\hline
\end{tabular}

Volume for fraction F5 is $115 \mathrm{~mL}$ for $\mathrm{F}$ and B samples, and $85 \mathrm{~mL}$ for NC and NB samples. Different letters in a same row identify significant differences ( $p<0.05$ ). Data are expressed as mean \pm stand ard deviation. Eq: equivalent; Antiox: antioxidant; TEAC: Trolox equivalent antioxidant capacity. 
Table 3. Curve fit parameters obtained from the model $f(y)=(a \cdot x) /(b+x)$ applied to extraction of melanoidins, browning, antioxidant capacity, and chlorogenic acids (CGA) in samples from filter-paper pods (F), FAP capsule (B), and clone capsule (NC, and NB).

\begin{tabular}{|c|c|c|c|c|}
\hline & $F$ & $B$ & NC & NB \\
\hline \multicolumn{5}{|l|}{ Melanoidins } \\
\hline a parameter & $115.5 \pm 1.71$ & $115.6 \pm 6.32$ & $119.3 \pm 4.8$ & $115.7 \pm 2.48$ \\
\hline b parameter & $16.7 \pm 0.73$ & $22.7 \pm 3.40$ & $12.2 \pm 1.5$ & $13.9 \pm 0.89$ \\
\hline$r^{2}$ & 0.999 & 0.991 & 0.993 & 0.998 \\
\hline$P$ & $<0.0001$ & $<0.0001$ & $<0.0001$ & $<0.0001$ \\
\hline$V_{50}(\mathrm{~mL})$ & $12.6 \pm 0.19 c$ & $18.0 \pm 0.8 \mathrm{~d}$ & $8.97 \pm 0.36 a$ & $10.63 \pm 0.23 b$ \\
\hline$V_{95}(\mathrm{~mL})$ & $77.3 \pm 1.44 c$ & $104.7 \pm 5.72 d$ & $47.8 \pm 1.92 \mathrm{a}$ & $63.8 \pm 1.37 b$ \\
\hline$V_{\max }(\mathrm{mL})$ & $107.8 \pm 1.60 c$ & $115.0 \pm 6.29 c$ & $63.1 \pm 2.53 \mathrm{a}$ & $85.0 \pm 1.82 b$ \\
\hline Espresso $(\mathrm{F} 4, \%)$ & $84.8 \pm 0.26 b$ & $77.4 \pm 0.38 a$ & $94.3 \pm 1.27 d$ & $88.9 \pm 0.56 c$ \\
\hline \multicolumn{5}{|l|}{ Browning } \\
\hline a parameter & $120.5 \pm 2.80$ & $126.7 \pm 8.67$ & $114.1 \pm 3.93$ & $114.8 \pm 4.59$ \\
\hline$b$ parameter & $21.7 \pm 1.40$ & $24.9 \pm 4.57$ & $9.9 \pm 1.14$ & $9.0 \pm 1.24$ \\
\hline$r^{2}$ & 0.998 & 0.988 & 0.994 & 0.991 \\
\hline$P$ & $<0.0001$ & $<0.001$ & $<0.0001$ & $<0.0001$ \\
\hline$V_{50}(\mathrm{~mL})$ & $15.3 \pm 0.36 c$ & $16.2 \pm 1.11 \mathrm{c}$ & $7.6 \pm 0.26 a$ & $7.0 \pm 0.28 b$ \\
\hline$V_{95}(\mathrm{~mL})$ & $80.9 \pm 1.88 c$ & $74.6 \pm 5.10 c$ & $49.5 \pm 1.71 b$ & $43.2 \pm 1.73 \mathrm{a}$ \\
\hline$V_{\max }(\mathrm{mL})$ & $106.5 \pm 2.48 c$ & $93.0 \pm 6.36 c$ & $70.4 \pm 2.43 b$ & $60.8 \pm 2.43 a$ \\
\hline Espresso $(\mathrm{F} 4, \%)$ & $81.8 \pm 0.21 \mathrm{a}$ & $82.2 \pm 0.31 b$ & $93.8 \pm 1.29 \mathrm{c}$ & $96.0 \pm 1.64 \mathrm{~d}$ \\
\hline \multicolumn{5}{|c|}{ Antioxidant activity } \\
\hline a parameter & $119.7 \pm 3.96$ & $120.5 \pm 2.91$ & $114.2 \pm 2.83$ & $115.6 \pm 1.37$ \\
\hline$b$ parameter & $20.1 \pm 1.88$ & $24.6 \pm 1.60$ & $11.9 \pm 093$ & $12.8 \pm 0.47$ \\
\hline$r^{2}$ & 0.996 & 0.998 & 0.997 & 0.999 \\
\hline$P$ & $<0.0001$ & $<0.0001$ & $<0.0001$ & $<0.0001$ \\
\hline$V_{50}(\mathrm{~mL})$ & $14.4 \pm 0.48 b$ & $17.1 \pm 0.41 \mathrm{c}$ & $9.3 \pm 0.23 \mathrm{a}$ & $9.6 \pm 0.11 a$ \\
\hline$V_{95}(\mathrm{~mL})$ & $77.3 \pm 2.55 b$ & $91.6 \pm 2.21 \mathrm{c}$ & $59.1 \pm 1.47 a$ & $61.1 \pm 0.72 \mathrm{a}$ \\
\hline$V_{\max }(\mathrm{mL})$ & $102.0 \pm 3.37 \mathrm{~b}$ & $115 c$ & $84.0 \pm 2.08 a$ & $82.3 \pm 0.98 a$ \\
\hline Espresso $(\mathrm{F} 4, \%)$ & $83.3 \pm 0.38 b$ & $78.5 \pm 0.12 \mathrm{a}$ & $90.7 \pm 0.78 c$ & $90.4 \pm 0.35 c$ \\
\hline \multicolumn{5}{|l|}{ CGAs } \\
\hline a parameter & $116.1 \pm 7.19$ & $119.04 \pm 5.58$ & $112.0 \pm 4.20$ & $115.3 \pm 5.10$ \\
\hline$b$ parameter & $11.0 \pm 2.42$ & $4.7 \pm 2.35$ & $7.7 \pm 1.05$ & $8.9 \pm 1.36$ \\
\hline$r^{2}$ & 0.981 & 0.992 & 0.992 & 0.989 \\
\hline$P$ & $<0.001$ & $<0.001$ & $<0.001$ & $<0.001$ \\
\hline$V_{50}(\mathrm{~mL})$ & $8.1 \pm 0.50 c$ & $12.6 \pm 0.60 \mathrm{~d}$ & $6.3 \pm 0.24 a$ & $7.0 \pm 0.31 \mathrm{~b}$ \\
\hline$V_{95}(\mathrm{~mL})$ & $49.4 \pm 3.06 a$ & $67.8 \pm 3.18 b$ & $42.8 \pm 1.61 \mathrm{a}$ & $41.8 \pm 1.85 a$ \\
\hline$V_{\max }(\mathrm{mL})$ & $68.3 \pm 4.23 \mathrm{a}$ & $90.3 \pm 3.18 b$ & $64.1 \pm 2.40 \mathrm{a}$ & $58.4 \pm 2.58 \mathrm{a}$ \\
\hline Espresso $(\mathrm{F} 4, \%)$ & $93.7 \pm 2.41 b$ & $86.8 \pm 0.69 a$ & $96.0 \pm 2.17 b$ & $96.6 \pm 2.24 b$ \\
\hline
\end{tabular}

$V_{50}$ (volume needed to extract the 50\%), $V_{95}$ (volume needed to extract the $95 \%$ ), $V_{\max }$ (volume needed to extract the maximum), and percentage extracted for espresso (fraction F4, $46 \mathrm{~mL}$ ). Different letters in a same row identify significant differences $(p<0.05)$. Data are expressed as mean \pm standard deviation. 
Figure I. Temperature-volume $\left({ }^{\circ} \mathrm{C} / \mathrm{mL}\right)$ profile at the exit and in-cup of the espresso coffeemakers used for filter-paper pods (a), FAP capsule (b), and clone capsule (c). Dotted lines represent the volumes for sampling. FI (5mL), F2 (9mL), F3 ( $16 \mathrm{~mL})$, F4 $(46 \mathrm{~mL})$, and F5 (II5 mL for a and b) and F5* (85 mL for c).
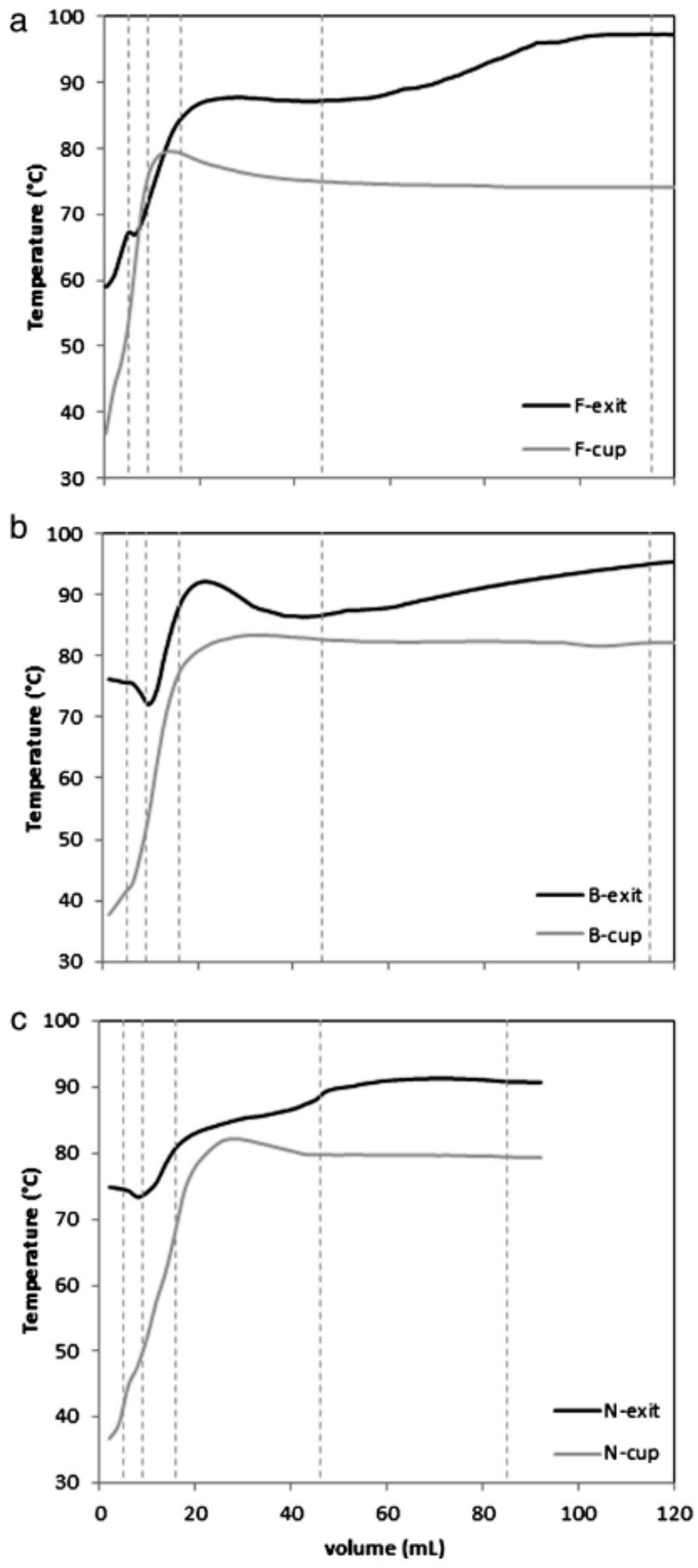

C. Bartel, M. Mesías, F.J. Morales / Food Research International 67 (20I5) 356-365 
Figure 2. Extraction rate (\%) for espresso coffeemaker and single-dose container. Filter-paper pods (F), FAP capsule (B), clone capsule (NC), and clone capsule containing a blend of Robusta and Arabica ground coffee (NB).

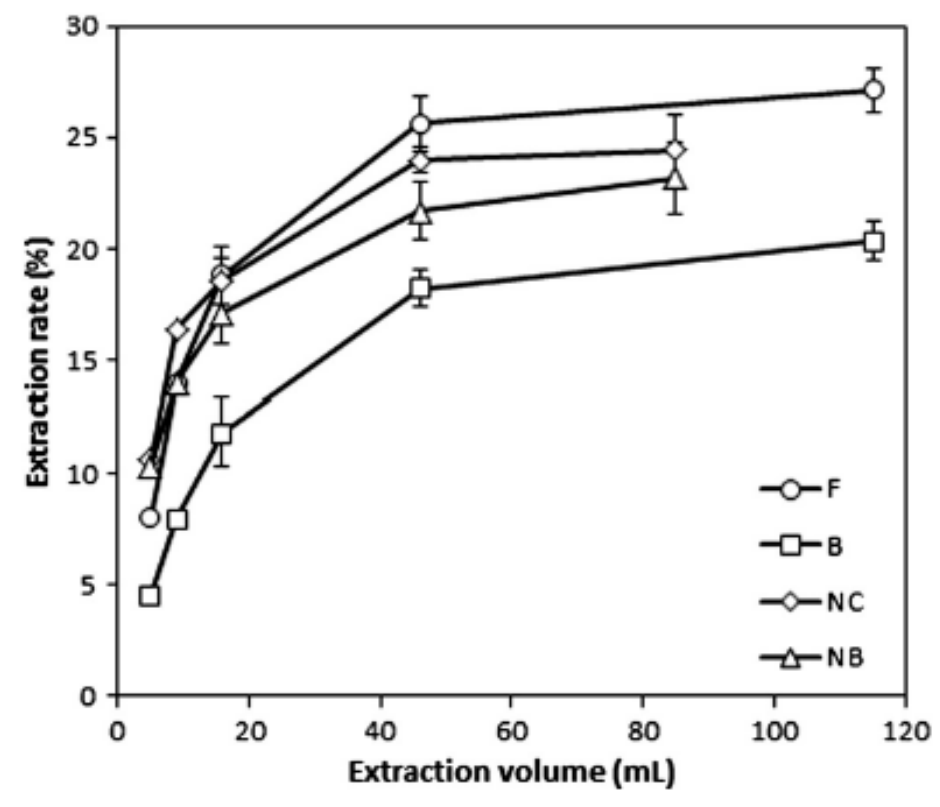


Figure 3. Extraction kinetics of melanoidins (a), browning (b), antioxidant capacity (c), and chlorogenic acids (d) normalized to fraction F5 for paper-filter pods (F), FAP capsules (B), and clone capsules (NC). Lines correspond to non-linear model adjustment.
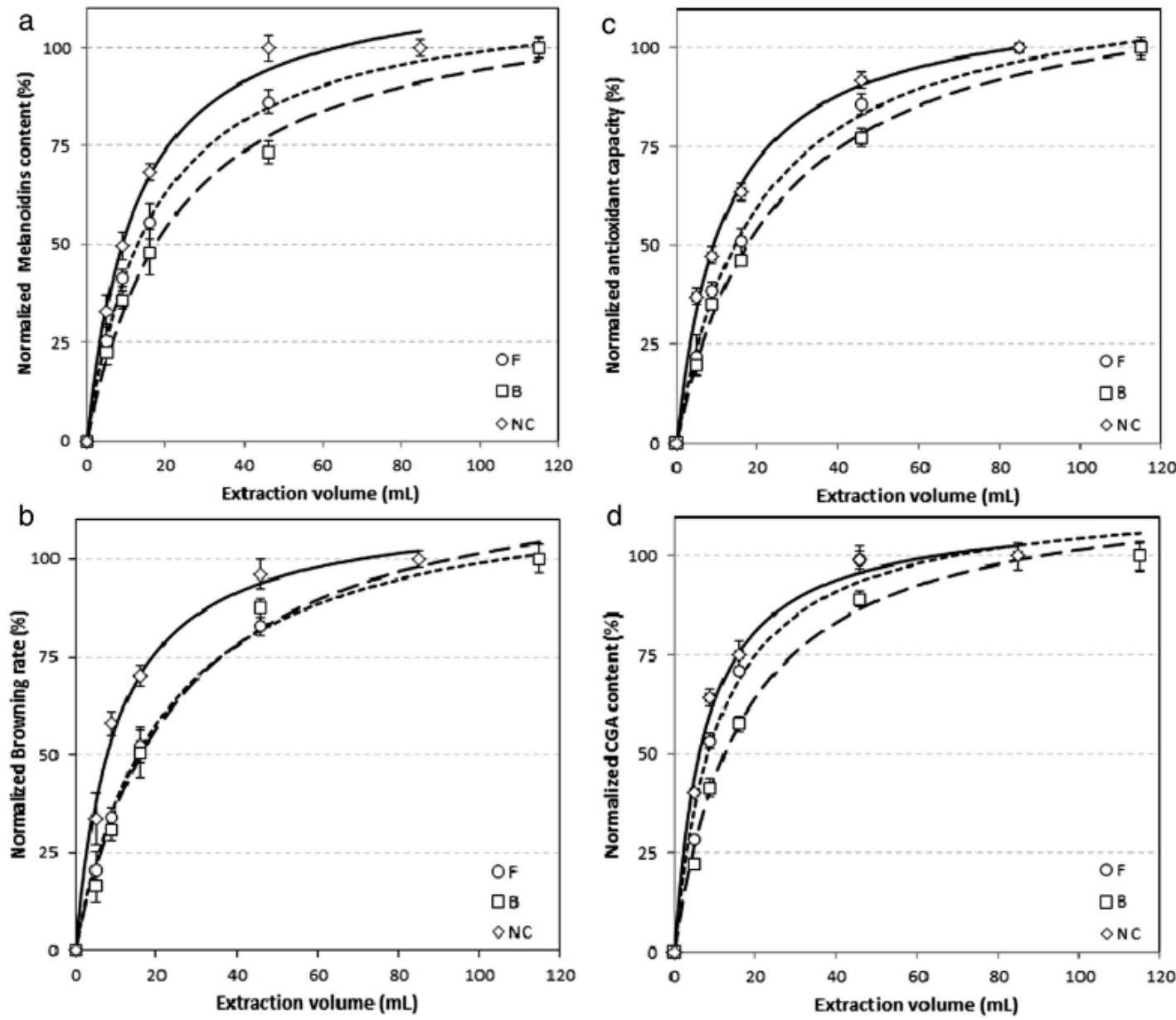
Figure 4. Relationship between antioxidant capacity and solids, melanoidins, browning, and chlorogenic acids (CGA) normalized to fraction F5 for paper-filter pods (F; a), FAP capsules (B; b), and clone capsules (NC; c, and NB; d). Data are expressed in percentage of the specific parameter to its total content (solids,melanoidins, and chlorogenic acids), activity (antioxidant), or rate (browning).
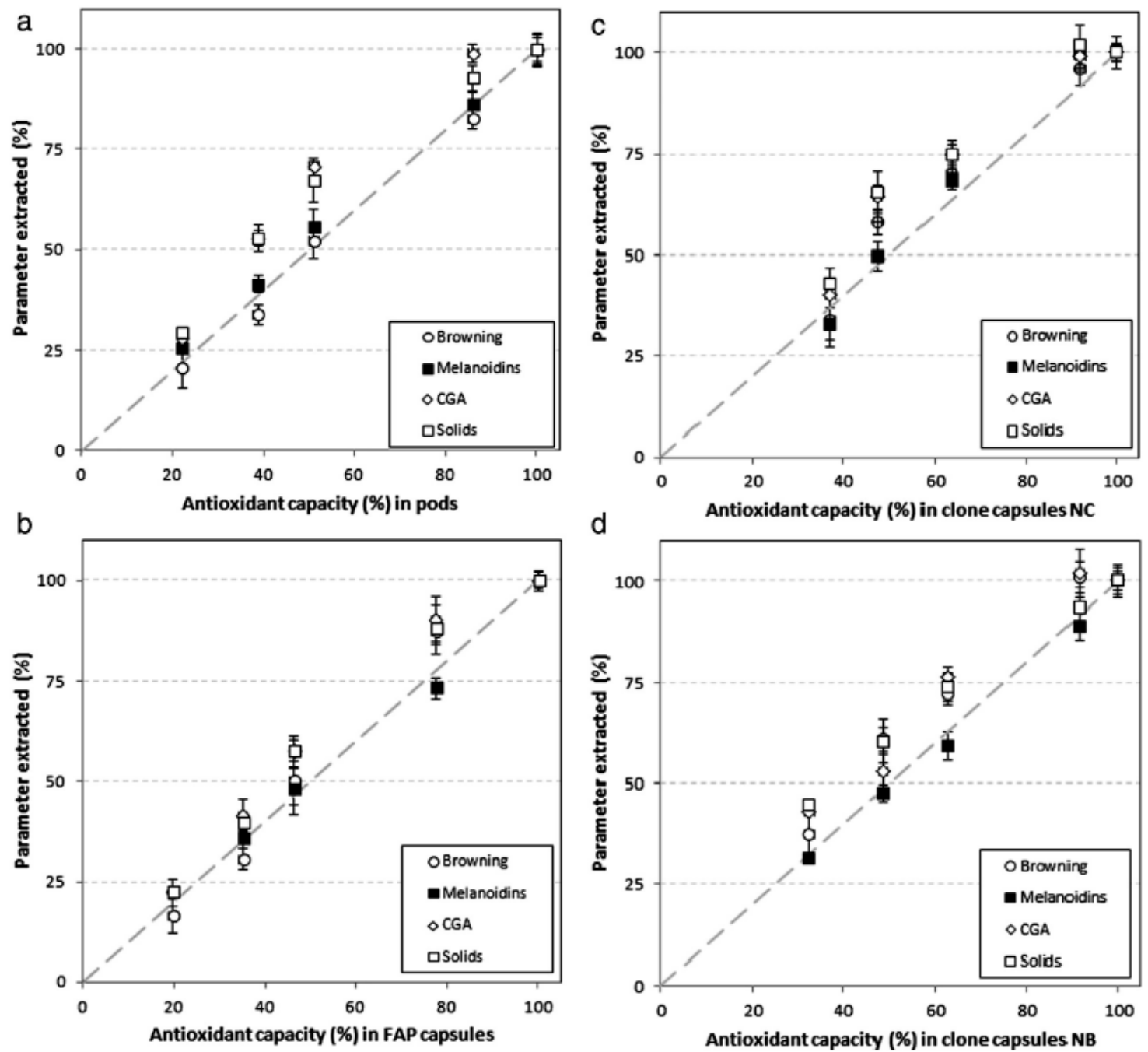
Figure 5. Antioxidant capacity (TEAC expressed as $\mu$ mol Trolox/g) for high molecular weight (HMW), low molecular weight (LMW) material, and melanoidin populations (Et50, Et75, and Sn75) in fractions $\mathrm{FI}, \mathrm{F} 3$, and F4 obtained from filter-paper pods. Different letters in a same sample identify significant differences ( $p b$ 0.05). Et50: insoluble at ethanol 50\%, Et75: insoluble at ethanol 75\%, and Sn75: soluble at ethanol $75 \%$.

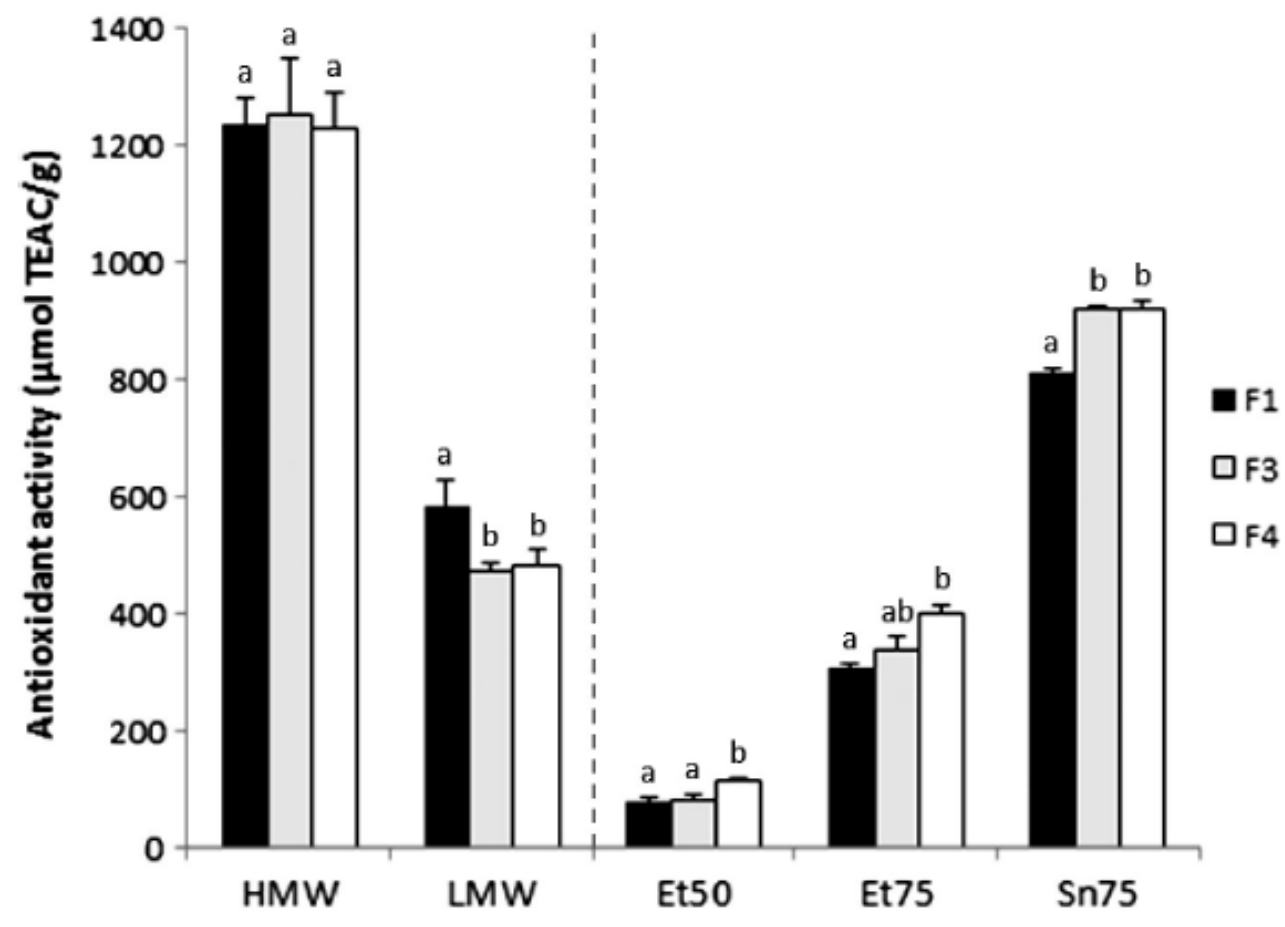

